\title{
The Relationship between Transformational Leadership of Immediate Superiors, Organizational Culture, and Affective Commitment in Fitness Club Employees
}

\author{
Kyongmin Lee ${ }^{1}$, Woojeong $\mathrm{Cho}^{2}$ \\ ${ }^{1}$ Chung-Ang University, College of Sport Sciences, Anseong, Korea, ${ }^{2}$ Korea Maritime \& Ocean University, Department of Ocean Physical Education, \\ Busan, Korea
}

\begin{abstract}
In an uncertain global business environment, effective human resource management is a crucial element in improving organizational effectiveness. However, relatively little research has examined the characteristics of transformational leadership and the types of organizational culture suitable for improving organizational effectiveness in the sport management field. Thus, the purpose of this study was to examine the relationship between transformational leadership of immediate superiors, organizational culture, and affective commitment in fitness club employees. For this purpose, a survey was given to a convenience sample of 300 employees of fitness clubs working in the Gwangju and Dae-gu metropolitan cities in South Korea. The data were then analyzed using descriptive statistics, correlations, and multiple regression analysis. The major findings of this study were as follows. First, transformational leadership had a significant effect on the organizational culture in fitness clubs. Second, transformational leadership had a significant effect on affective commitment of employees of the fitness clubs. Third, organizational culture had a significant effect on affective commitment of employees in fitness clubs. The findings of this study may be helpful for fitness clubs to determine the characteristics of transformational leadership and the types of organizational culture needed to improve affective commitment of employees.
\end{abstract}

Key words: affective commitment, fitness clubs in South Korea, organizational culture, transformational leadership

\section{Introduction}

In today's increasingly complex business environment, many companies strive to gain competitive advantages to meet the demands of diverse consumers and to survive and develop in the intense competition between companies. Although concerted efforts are needed to improve organizational performance under these conditions, the first strategy companies can consider is efficient management of human resources. Given that leadership is conceptualized as a series of activities that integrate and coordinate the efforts of organization members, motivate them, and exert their influence in the manage- ment process to achieve the goals of the organization (Bass, 1998), leadership can be considered a key factor for efficient human resource management.

Because transformational leadership is perceived as a leadership style suitable for uncertain or crisis situations (Yukl \& Howell, 1999), there have been many studies of the relationship between transformational leadership and organizational effectiveness in a variety of areas. For example, Walumbwa, Orwa, Wang, and Lawler (2005) used financial firms in the United States and Kenya to conduct a comparative cultural study of the effects of transformational leadership on job sat-

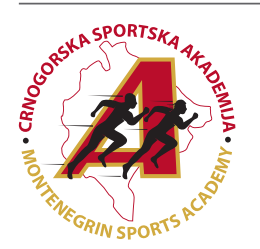

Correspondence:

W. Cho

Korea Maritime \& Ocean University, Department of Ocean Physical Education, 727 Taejong-ro, Yeongdo-Gu, Busan, Korea

E-mail: mikecho@kmou.ac.kr 
isfaction and organizational commitment. Njoroge, Gachunga, and Kihoro (2015) examined the mediating effects of employee participation in the relationship between transformational leadership and organizational commitment by using instructors of technical schools in Kenya.

A rapidly changing market environment is challenging for any organization, and sports organizations are no exception. Sports organizations have limited human and material resources internally and should be able to compete infinitely in the global market externally. Thus, as part of efficient HR management, several recent studies in sport management have dealt with the effects of transformational leadership on organizational effectiveness, such as job satisfaction, athlete satisfaction, and organizational commitment (Hallajy, Janani, \& Fallah, 2011; Kent \& Chelladurai, 2001). As Wallace and Weese (1995) pointed out, however, empirical studies on the causal relationship between transformational leadership and organizational effectiveness in sport management are inadequate.

Additionally, based on the results of previous studies that concluded that establishing management strategy suitable for organizational culture type and for understanding organizational culture accurately play a key role in enhancing organizational effectiveness (Acar, 2012; Shoaib, Zainab, Maqsood, \& Sana, 2013), further research is required to empirically examine the relationship between transformational leadership, organizational culture, and organizational effectiveness, in order to establish a comprehensive and systematic strategy for the survival and development of sports organizations in a rapidly changing business environment. Accordingly, this study sought to explore the relationship between transformational leadership of immediate superiors, organizational culture, and affective commitment of employees working at fitness clubs in South Korea.

Regarding the relationship between transformational leadership, organizational culture, and affective commitment, relevant literature shows that transformational leadership directly or indirectly affects organizational culture. Acar (2012) argued that charisma, one sub factor of transformational leadership, had a significant effect on hierarchical culture, that inspirational motivation had a significant effect on clan culture and hierarchical culture, and that individualized consideration had a significant effect on clan culture. Rasid, Manaf, and Quoquab (2013) suggested the importance of mediating effect of organizational culture because leadership influenced organizational commitment indirectly through organizational culture. Also, the relationship between the two variables has been found in the sports field. In a study of taekwondo leaders in Korea, (a) the idealized influence had a significant influence on the consensus culture and rational culture; (b) the individualized consideration had a significant influence on the consensus culture, rational culture and innovation culture; and (c) the inspirational motivation had a significant influence on bureaucracy culture (Park, 2011). Based on this literature, this study formulated the following research hypothesis in terms of the relationship between transformational leadership and organizational culture.

Hypothesis 1: Transformational leadership of immediate superiors in fitness clubs will have an effect on organizational culture.

In relation to the relationship between transformational leadership and affective commitment, it has been found that transformational leadership has a positive influence on affec- tive commitment in various fields. In a comparative study of financial institutions in Kenya and the United States, a significant positive relationship was found between the two variables (Walumbwa, Orwa, Wang, \& Lawler, 2005). Also, in a study of Egyptian workers in seven industries (e.g., telecommunications, education, energy, manufacturing, pharmaceuticals, business services, and financial services), transformational leadership was found to have a positive effect on affective commitment (ElKordy, 2013). Furthermore, in a study of employees working at a college physical education department in the Midwest of the United States, sub dimensions of transformational leadership, including intellectual stimulation, charism, and individualized consideration, showed a significant positive correlation with affective commitment (Kent \& Chelladurai, 2001). Based on the results of those studies, this study formulated the following research hypothesis concerning the relationship between transformational leadership and affective commitment.

Hypothesis 2: Transformational leadership of immediate superiors in fitness clubs will have an effect on the employee's affective commitment.

No consensus has been reached on the relationship between organizational culture and affective commitment. Kim (2007) said that consensus culture, developmental culture, and rational culture did not have a significant effect on organizational commitment, but that the hierarchical culture had a significant positive influence on organizational commitment. Acar (2012) argued that clan culture and market culture made unique contributions to affective commitment, but that hierarchical culture and market culture had no significant effects on affective commitment. Shoaib, Zainab, Maqsood, and Sana (2013) suggested that only clan culture among the organizational culture types had a positive correlation with affective commitment. Based on the results of these studies, this study formulated the following research hypothesis regarding the relationship between organizational culture and affective commitment.

Hypothesis 3: The organizational culture of a fitness club will have an effect on affective commitment of its employees.

\section{Methods \\ Participants}

The subjects of this study were selected from employees working at fitness clubs in Gwangju and Dae-gu metropolitan cities in South Korea. Based on a convenience sampling method, a total of 300 valid questionnaires were used for data analysis, 152 from private fitness clubs and 148 from public fitness clubs. Of the 300 respondents, 166 (55.3\%) were men, and 134 (44.7\%) were women. Those between 20 and 30 years of age represented higher percentage than other age groups, accounting for $40 \%$ and $44 \%$, respectively. The majority of the respondents $(68 \%)$ had attained a bachelor's degree. In terms of their current job position, 192 (64\%) described it as fitness instructor, $76(25.3 \%)$ as regular worker, and $26(8.7 \%)$ as manager.

\section{Measures}

A survey instrument was used to measure transformational leadership, organizational culture, and affective commitment. The questions were measured with a Likert scale of 5 points, from $1=$ strongly disagree to $5=$ strongly agree. To establish content validity, a panel of experts was asked to verify the ap- 
propriateness and the representativeness of the questionnaires. The construct validity and reliability of the questionnaires were verified through exploratory factor analysis and internal consistency analysis, respectively.

The Multifactor Leadership Questionnaire (MLQ) developed by Avolio and Bass (2004) was adapted into Korean and modified for use to measure the transformational leadership of immediate superiors in fitness clubs. The transformational leadership questionnaire consisted of three factors: charisma, intellectual stimulation, and individualized consideration. Each factor was comprised of six items. Principal component analysis with varimax rotation revealed that the three factors explained a total of $69.023 \%$ of the variance. Two items of the intellectual stimulation factor were excluded, so a total of 16 items was used to measure the transformational leadership questionnaire. The alpha values for the 16 items ranged from 0.810 to 0.912 , which indicates that the transformational leadership questionnaire was proven to have sufficient reliability.

Additionally, the questionnaire originally developed by Quinn and McGrath (1995) was adapted into Korean and modified for use to measure organizational culture. The organizational culture questionnaire consisted of four factors: developmental culture, consensus culture, rational culture, and hierarchical culture. Each factor had four items. According to principal component analysis with varimax rotation, all of the items derived from the previous study were converged, and the four factors accounted for a total of $73.626 \%$ of the variance. The reliability of the organizational culture questionnaire was found to be sufficient with the alpha values between 0.778 and 0.919 .

Finally, the questionnaire used by Goo (2014), Meyer and Allen (1991), Shim and Choi (2014) was modified for use to measure affective commitment. The affective commitment questionnaire was composed of five items as a single factor.

\section{Data analysis}

The 300 valid questionnaires collected in this study were analyzed with the SPSS 23.0 statistical program. To determine the levels of transformational leadership, organizational culture, and affective commitment, a descriptive statistics analysis was run. Also, the relationship between each variable was verified through correlations analysis and multiple regression analysis. All statistical significance tests of this study were verified at $\alpha=0.05$ level.

\section{Results \\ Descriptive statistics and correlations results}

In terms of descriptive statistics results, the dimensions of transformational leadership were ranked in order of intellectual stimulation $(M=3.48)$, charisma $(M=3.37)$ and individualized consideration $(\mathrm{M}=3.32)$. The most common type of organizational culture was hierarchical culture $(M=3.64)$, followed by consensus culture $(M=3.60)$, rational culture $(M=3.59)$, and developmental culture $(\mathrm{M}=3.53)$. Regarding correlations between the study variables, the dimensions of transformational leadership had significant correlations with affective commitment, and the strongest positive correlation was between individualized consideration and affective commitment, $\mathrm{r}=0.53$, $\mathrm{p}<0.001$. Additionally, the factors of organizational culture had significant correlations with affective commitment, and consensus culture had the strongest positive correlation with affective commitment, $\mathrm{r}=0.65, \mathrm{p}<0.001$.

\section{Results of multiple regression analysis}

As for the effects of transformational leadership on organizational culture, the dimensions of transformational leadership had statistically significant effects on the types of organizational culture. As shown in Table 1, transformational leadership of immediate superiors explained $26.4 \%$ of the variance in consensus culture $\left(\mathrm{R}^{2}=0.26, \mathrm{p}<0.001\right)$, and individualized consideration $(\beta=0.34, p<0.001)$ made the strongest unique contribution to explaining consensus culture. Some $36.4 \%$ of the variance in developmental culture was explained from transformational leadership of the immediate superior $\left(\mathrm{R}^{2}=0.36\right.$, $\mathrm{p}<0.001)$, and individualized consideration $(\beta=0.36, \mathrm{p}<0.05)$ made the strongest unique contribution to the prediction of developmental culture. The transformational leadership accounted for $26 \%$ of the variance in rational culture $\left(R^{2}=0.26\right.$, $\mathrm{p}<0.001)$, and individualized consideration $(\beta=0.29, \mathrm{p}<0.001)$ had the strongest unique contribution to predicting rational culture. Some $24.2 \%$ of the variance in hierarchical culture was explained from the transformational leadership $\left(\mathrm{R}^{2}=0.24\right.$, $\mathrm{p}<0.001$ ), and charisma had the strongest unique contribution for explaining hierarchical culture $(\beta=0.33, \mathrm{p}<0.001)$.

Table 1. Multiple Regression Analysis Summary for Charisma, Intellectual Stimulation, and Individualized Consideration Predicting Organizational Culture

\begin{tabular}{|c|c|c|c|c|c|c|c|c|c|c|c|c|}
\hline \multirow[b]{2}{*}{ Variable } & \multicolumn{3}{|c|}{ Consensus } & \multicolumn{3}{|c|}{ Developmental } & \multicolumn{3}{|c|}{ Rational } & \multicolumn{3}{|c|}{ Hierarchical } \\
\hline & B & SEB & $\beta$ & B & SEB & $\beta$ & B & SEB & $\beta$ & B & SEB & $\beta$ \\
\hline Charisma & 0.142 & 0.069 & $0.161^{*}$ & 0.333 & 0.077 & $0.315^{* * *}$ & 0.197 & 0.074 & $0.208^{* * *}$ & 0.294 & 0.071 & $0.329^{* * *}$ \\
\hline IntStim & 0.068 & 0.083 & 0.065 & 0.019 & 0.092 & 0.015 & 0.074 & 0.089 & 0.066 & 0.015 & 0.085 & 0.014 \\
\hline IndCon & 0.312 & 0.068 & $0.339^{* * *}$ & 0.394 & 0.075 & $0.357^{* * *}$ & 0.289 & 0.073 & $0.292^{*}$ & 0.181 & 0.070 & $0.194^{*}$ \\
\hline $\mathrm{R}^{2}$ & \multicolumn{3}{|c|}{0.264} & \multicolumn{3}{|c|}{0.364} & \multicolumn{3}{|c|}{0.260} & \multicolumn{3}{|c|}{0.242} \\
\hline $\mathrm{F}$ & \multicolumn{3}{|c|}{$34.393^{* * *}$} & \multicolumn{3}{|c|}{$55.280^{* * *}$} & \multicolumn{3}{|c|}{$34.012^{* * *}$} & \multicolumn{3}{|c|}{$30.908^{* * *}$} \\
\hline
\end{tabular}

Note. IntStim: intellectual stimulation; IndCon: individualized consideration; ${ }^{*} \mathrm{p}<.05$. ${ }^{* * *} \mathrm{p}<.001$

Regarding the effects of transformational leadership of the immediate superior on affective commitment of employees, the dimensions of transformational leadership had statistically significant effects on affective commitment. As shown in Table 2 , transformational leadership explained $32.7 \%$ of the variance in affective commitment $\left(\mathrm{R}^{2}=0.33, \mathrm{p}<0.001\right)$, and individual- ized consideration made the strongest unique contribution to the prediction $(\beta=0.33, \mathrm{p}<0.001)$.

Finally, in relation to the effects of organizational culture on affective commitment of employees, the dimensions of organizational culture had statistically significant effects on affective commitment. As shown in Table 3, the organizational 
Table 2. Multiple Regression Analysis Summary for Charisma, Intellectual Stimulation, and Individualized Consideration Predicting Affective Commitment

\begin{tabular}{lccc}
\hline & \multicolumn{3}{c}{ Affective Commitment } \\
Variable & B & SEB & $\beta$ \\
\hline Charisma & 0.153 & 0.067 & $0.171^{*}$ \\
IntStim & 0.148 & 0.080 & 0.139 \\
IndCon & 0.305 & 0.066 & $0.327^{* * *}$ \\
R $^{2}$ & & 0.327 & \\
F & & $46.963^{* * *}$ & \\
\hline
\end{tabular}

Note. IntStim: intellectual stimulation; IndCon: individualized consideration; ${ }^{*} \mathrm{p}<.05 .{ }^{* * *} \mathrm{p}<.001$

culture accounted for $54 \%$ of the variance in affective commitment $\left(R^{2}=0.54, p<0.001\right)$, and consensus culture $(\beta=0.24$, $\mathrm{p}<0.001)$ had the strongest unique contribution to explaining affective commitment, followed by developmental culture $(\beta=0.24, p<0.001)$, rational culture $(\beta=0.20, p<0.01)$, and hierarchical culture $(\beta=0.19, \mathrm{p}<0.001)$.

Table 3. Multiple Regression Analysis Summary for Consensus, Developmental, Rational, and Hierarchical Cultures Predicting Affective Commitment

\begin{tabular}{lccc}
\hline \multirow{2}{*}{ Variable } & \multicolumn{3}{c}{ Affective Commitment } \\
\hline Consensus & B & SEB & $\beta$ \\
Developmental & 0.242 & 0.062 & $0.242^{* * *}$ \\
Rational & 0.203 & 0.058 & $0.240^{* * *}$ \\
Hierarchical & 0.184 & 0.055 & $0.198^{* * *}$ \\
$\mathrm{R}^{2}$ & 0.192 & 0.054 & $0.194^{* * *}$ \\
$\mathrm{~F}$ & & 0.535 & \\
\hline
\end{tabular}

${ }^{* * *} \mathrm{p}<.001$

\section{Discussion}

This study was conducted to empirically examine the effects of transformational leadership of immediate superiors and organizational culture on affective commitment of employees in fitness clubs in South Korea. The following discussion is presented based on the results of this study and previous studies. Transformational leadership of the immediate superior had positive effects on organizational culture. Especially, this study shows that the charisma leadership of immediate superiors made the largest unique contribution to forming the hierarchical culture. This result may indicate that the type of hierarchical culture that features control, efficiency, and stability can be further strengthened when a fitness club's immediate superior provides specific goals and ideals and directs the employees to follow the proposed vision.

Additionally, it was found that the individualized consideration leadership made the strongest unique contribution to forming consensus, developmental, and rational culture types. This result is in accordance with the findings of Lee's study (2014). However, the individualized consideration level $(\mathrm{M}=3.32)$ perceived by current employees of fitness club was found to be the lowest as compared to the levels of charisma
$(M=3.37)$ and intellectual stimulation $(M=3.48)$. This may suggest that to improve consensus, developmental, and rational culture types in fitness clubs, leaders should be actively interested and caring for their members, and should strengthen direct contact and two-way communication.

On the other hand, the intellectual stimulation leadership had no statistically significant effects on all sub factors of organizational culture. This result is similar to what Acar (2012) presented. This may occur because dominant culture types in the fitness clubs that were studied were hierarchical culture $(\mathrm{M}=3.64)$ and consensus culture $(\mathrm{M}=3.60)$. As Kim (2007) pointed out, a more controllable leadership styleis required in the case of an organization with a strong hierarchical culture type that focuses on seeking efficiency on a stable basis, whereas a leadership type that encourages commitment to the organization through active care and consideration for individuals is required in an organization with a strong consensus culture type that emphasizes the development of human resources. In this manner, intellectually stimulating leadership, a way for leaders to help the members approach their own problems through new ways when they face a problem, does not seem to be suitable for the organizational culture of the current fitness club.

As for the effects of transformational leadership on affective commitment, transformational leadership of the immediate superior had positive effects on the affective commitment of the employee. Specifically, only individualized consideration and charisma were contributing to explaining the employees' affective commitment. This result shows that the level of psychological attachment to the organization felt by the employees of the fitness clubs can be changed according to the degree to which the clubs' superiors care about employees individually by identifying their needs and that employees of fitness clubs also can increase their psychological attachment to the organization when they recognize that the immediate superior has a specific vision for the organization.

Finally, the dimensions of organizational culture were found to affect the employee's affective commitment. This result is consistent with what Acar (2012) and Shoaib, Zainab, Maqsood, and Sana (2013) presented. The type of organizational culture that made the strongest unique contribution to the prediction of affective commitment was consensus culture. This result may occur because consensus culture $(M=3.60)$ was one of the main types of organizational cultures that employees of the current fitness club recognized. Thus, to enhance the emotional commitment of fitness club employees, fitness clubs need to implement personnel management strategies suitable for strengthening the consensus culture elements that emphasize human relations and the atmosphere, morale, and teamwork within the organization.

Also of note in terms of the effects of organizational culture on affective commitment is the relationship between hierarchical culture and affective commitment. Considering that the organization with a relatively strong hierarchical culture type has an attribute that emphasizes compliance with rules and procedures (Kim, 2007), it was expected that hierarchical culture would have a negative impact on affective commitment. However, this study found that the hierarchical culture of fitness clubs had a positive effect on the employees' affective commitment. This may be due to the internal and external business environments of Korean fitness clubs (Kim, Lee, \& Jung, 2007; Kim \& Sul, 2002). Internally, fitness clubs in Ko- 
rea have difficulties securing new consumers due to intensified competition among companies, aging of facilities and equipment, small size, and limitations of human and material resources. Externally, domestic economic depression makes it difficult for consumers to dispend, and the appearance of a foreign brand of fitness club with a strong capital base leads to a decline in operating profit and to profitability deterioration. In this context, employees of fitness clubs seem to have positively embraced a hierarchical culture that emphasizes control or coordination of the organization for the stability and survival of the organization.

The results of this study are meaningful in providing the basic data needed to determine the characteristics of transformational leadership and the types of organizational culture necessary for improving the emotional engagement of employees of fitness clubs by applying the results of previous research related to management strategy that identifies the causal relationship between transformational leadership, organizational culture, and affective commitment to sport management. However, due to some limitations in the design and methodological aspects of the study, several things need to be supplemented in further research. First, this study was conducted with fitness club employees working in the Korean metropolitan cities of Gwangju and Daegu. Thus, the results of this study may not be directly applicable to fitness clubs in other countries. Future research is recommended to investigate the causality between transformational leadership, organizational culture, and affective commitment by using a sample of fitness club employees in other countries. Second, given that this study focused on a cross-sectional study that analyzed the degree of emotional involvement of fitness club workers at a particular time in connection with transformational leadership and organizational culture types, it would be necessary to carry out an empirical analysis through longitudinal research in future research. Finally, this study limited the measurement of organizational commitment to affective commitment. Thus, future research is recommended to classify organizational commitment into three sub factors, such as normative commitment, continuance commitment, and affective commitment.

\section{Acknowledgements \\ There are many people who we would like to thank for helping us finish this article. We would first like to express our gratitude to Mr. Jim Wagner, a certificate English proofreader who gave us encouragement and provided valuable feedback during the process of the writing. We also want to thank our colleagues at Korea Maritime \& Ocean University for their assistance and support in completing the article. Without their assistance and encourage- ment, we could not have completed the article successfully.}

\section{Conflict of Interest}

The authors declare there are no conflict of interest.

Received: 05 August 2017| Accepted: 11 September 2017

\section{References}

Acar, A.Z. (2012). Organizational culture, leadership styles and organizational commitment in Turkish logistic industry. Social and Behavioral Sciences, 58, 217-226.

Avolio, B.J. \& Bass, B.M. (2004). Multifactor leadership questionnaire: Manual and sampler set. ( $3^{\text {rd }}$ edition): Mind Garden.

Bass, B.M. (1998). Transformational leadership: Industrial, military and educational impact: Lawrence Erlbaum Associates.

ElKordy, M. (2013). Transformational leadership and organizational culture as predictors of employees attitudinal outcomes. Business Management Dynamics, 3(5), 15-26.

Goo, J.D. (2014). A study on the relationship among organizational culture, followership and organizational effectiveness in hotel industry. Journal of Tourism Industry Studies, 8(2), 1-18.

Hallajy, M., Janani, H., \& Fallah, Z. (2011). Modeling the effect of coaches' leadership styles on athletes' satisfaction and commitment in Iranian handball pro league. World Applied Sciences Journal, 14(9), 1299-1305.

Kim, H. (2007). A study on the causal relationships among organizational culture, leadership, and organizational commitment. Korean Society \& Public Administration, 18(2), 23-49.

Kim, H.M. \& Sul, M.S. (2002). Sports center business plan and strategy plan by society chance. The Korea Journal of Sports Science, 11(2), 183-190.

Kim, Y.M., Lee, K., \& Jung, J. (2007). Structural relationship among spectatorship value, team identification, team emotion and repurchase intention for professional baseball spectators. Korean Society for Sport Management, 12(3), 37-50.

Kent, A. \& Chelladurai, P. (2001). Perceived transformational leadership, organizational commitment, and citizenship behavior: A case study in intercollegiate athletics. Journal of Sport Management, 15, 135-159.

Lee, S.Y. (2014). The relationship between leaderships and organizational cultures of Chinese corporations. Journal of Business Research, 29(3), 129-171.

Meyer, J.P. \& Allen, N.J. (1991). A three-component conceptualization of organizational commitment. Human Resource Management Review, 1(1), 61-89.

Njoroge, D., Gachunga, H., \& Kihoro (2015). Transformational leadership style and organizational commitment: The moderating effect of employee participation. The Strategic Journal of Business \& Change Management, 2(6), 94-107.

Park, D. (2011). Relationship between the leadership types, organizational culture and organizational effectiveness by Taekwondo leaders. The Journal of Korean Alliance of Martial Arts, 13(2), 161-175.

Quinn, R.E. \& McGrath, M.R. (1985). Chapter 9- The transformation of organizational cultures: A competing values perspective ISBN: 9780803924604 Organizational Culture, 315-334.

Rasid, S.Z.A., Manaf, A.A., \& Quoquab, F. (2013). Leadership and organizational commitment in the Islamic banking context: The role of organizational culture as a mediator. American Journal of Economics, 3(5C), 171-176.

Shim, W.G. \& Choi, H.G. (2014). The effect of organizational culture on job satisfaction, customer, orientation and service delivery level in university. Journal of Creativity and Innovation, 7(2), 191-224.

Shoaib, A., Zainab, N., Maqsood, H., \& Sana, R. (2013). Impact of organizational culture on organizational commitment: A comparative study of public and private organizations. Research Journal of Recent Sciences, 2(5), 15-20.

Wallace, M. \& Weese, W.J. (1995). Leadership, organizational culture, and job satisfaction in Canadian YMCA organizations. Journal of Sport Management, 9, 182-193.

Walumbwa, F.O., Orwa, B., Wang, P., \& Lawler, J.J. (2005). Transformational leadership, organizational commitment, and job satisfaction: A comparative study of Kenyan and U.S. financial firms. Human Resource Development Quarterly, 16(2), 235-252.

Yukl, G.A. \& Howell, J.M. (1999). Organizational and contextual influences on the mergence and effectiveness of charismatic leadership. Leadership Quarterly, 10, 257-264. 